\title{
Caracterização dendroenergética de árvores de Eucalyptus benthamii
}

\author{
Edson Alves de Lima ${ }^{1}$, Helton Damin da Silva ${ }^{1}$, Osmir José Lavoranti ${ }^{1}$ \\ Embrapa Florestas, Km 111, CP 319, CEP 83411-000, Colombo, PR, Brasil, edson@cnpf.embrapa.br; helton@cnpf.embrapa.br; \\ osmir@cnpf.embrapa.br
}

\begin{abstract}
Resumo - Eucalyptus benthamii é a espécie que mais tem se destacado para finalidade energética em áreas de ocorrência de geadas. O objetivo deste trabalho foi classificar por ordem de importância as características dendroenergéticas de matrizes selecionadas para melhoramento dessa espécie. Foram coletados discos do DAP de 91 árvores de três áreas de plantio no Município de Guarapuava, PR, de coordenadas geográficas $25^{\circ} 23^{\prime} 26^{\prime \prime} \mathrm{S}$ e $51^{\circ} 27^{\prime} 15^{\prime}$ 'E, e $1.120 \mathrm{~m}$ de altitude. Na madeira avaliaram-se densidade básica, volume, massa, poder calorífico superior, densidade energética e potencial energético, e no carvão avaliaram-se rendimento, gases condensáveis e não condensáveis, carbono fixo, voláteis, cinzas, poder calorífico superior e potencial energético. A partir das características mensuradas, no campo e laboratório para cada indivíduo, efetuou-se a análise multivariada dos componentes principais e de fator com o objetivo de identificar as variáveis que apresentam maior contribuição para a variância total. Com vistas à obtenção de energia, deve-se dar maior importância para as variáveis: massa, volume, potencial energético da madeira e potencial energético do carvão.
\end{abstract}

Termos para indexação: Bioenergia, biomassa florestal, geada.

\section{Dendroenergetical characterization of Eucalyptus benthamii trees}

\begin{abstract}
Eucalyptus benthamii has shown to be the most proeminent specie for regions with frost incidence. The objective of this work was to classify selected Eucalyptus benthamii trees for breeding by importance ordening dendrometric and energetic characteristics, useful for this work 91 disks of DBH were collected, from three plantations at Guarapuava municipality, Parana state, with geographical coordinates $25^{\circ} 23^{\prime} 26^{\prime \prime} \mathrm{S}$ e $51^{\circ}$ $27^{\prime} 15^{\prime \prime} \mathrm{E}$ and 1,120 m high. Wood basic density, volume, mass, superior calorific power, energertic density and energetic potential were evaluated. Charcoal yield, condensed and non-condensable gases, fixed carbon, volatiles, ashes, superior calorific power and energetic potential were also evaluated. From the measured characteristics, at the field and laboratory for each individual, multivariable analysis were performed using the main compounds and factorial analysis with the aim of identifying those variables which presented larger contribution for total variance. At $E$. Benthamii tree selection for energy production, most of the attention should be driven to the variables mass, volume, wood energetic potential and charcoal energetic potential.
\end{abstract}

Index terms: Bioenergy, forest biomass, frost.

\section{Introdução}

Historicamente a biomassa florestal é considerada como uma importante fonte de energia (Couto et al., 2002). No Brasil, a biomassa participa com 32\% da matriz energética, sendo $13,9 \%$ a partir da lenha e do carvão (Brasil, 2010). Dos 321 milhões de metros cúbicos de madeira consumidos, $69 \%$ são destinados para geração de energia (Brito, 2007) e a demanda está assim distribuída: carvão para siderúrgicas - 39\%; setor residencial $-32 \%$; setor industrial - ramo de cimento, químico, alimentos, bebidas, papel celulose e cerâmicas $-21 \%$; e setor agrícola $-6 \%$ (Brito \& Cintra, 2004). Segundo Brito (2007), considerando o consumo médio anual de dois metros cúbicos de madeira per capta, estima-se que pelo menos 30 milhões de pessoas dependem da madeira como fonte de energia domiciliar no Brasil, principalmente para as classes menos favorecidas da população.

No Brasil, várias espécies de eucalipto foram testadas para atender a produção de lenha para energia, obedecendo apenas o zoneamento ecológico proposto por Golfari e Pinheiro Neto, em 1970, e somente mais tarde, a seleção com base nas características da madeira só foi considerada, especialmente para atender a produção de carvão vegetal e de celulose e papel. Posteriormente, vários trabalhos foram realizados para obter mais informações sobre a influência da qualidade 
da madeira na qualidade do carvão vegetal (Trugilho et al., 2001).

Com a necessidade de autosuficiência, as empresas siderúrgicas estão dando maior importância ao desenvolvimento de novas tecnologias de produção de madeira, avaliação da sua qualidade, bem como sua transformação em carvão vegetal. As avaliações que levam em consideração o potencial produtor do carvão e a sua qualidade têm se tornado uma rotina para as empresas que necessitam dessa matéria-prima (Instituto Nacional para Eficiência Energética, 2006).

Souza et al. (2004) avaliaram o comportamento de Acacia mangium e cinco clones do híbrido E. grandis $x$ E. urophylla na Amazônia Central. Os autores observaram que clones de urograndis apresentaram elevada diferença no incremento médio anual (IMA). Neste trabalho, o clone "0321" apresentou IMA de 34,0 $\mathrm{m}^{3}$ ha ano $^{-1}$ enquanto o clone " 1341 " teve IMA de 8,5 $\mathrm{m}^{3}$ ha ano $^{-1}$, ou seja, mais de $300 \%$ superior.

Nos estados do sul do Brasil, onde as temperaturas baixas e a ocorrência de geadas têm sido os principais fatores limitantes da sobrevivência e do crescimento dos eucaliptos, podemos destacar algumas poucas espécies que têm demonstrado tolerância. Dentre aquelas já plantadas, citam-se E. dunni, E. viminalis e recentemente $E$. benthamii Maiden et Cambage, que vem se destacando em função da tolerância a geada, crescimento, forma e capacidade de rebrota. Apesar do potencial de produção de biomassa, até o momento poucos estudos demonstraram o real potencial do $E$. benthamii para fins energéticos. Por isso, torna-se necessário caracterizar a qualidade energética desta espécie tanto da madeira quanto do carvão.
O objetivo deste trabalho foi classificar por ordem de importância as características dendrométricas e energéticas em árvores de $E$. benthamii.

\section{Material e métodos}

Foram coletados discos do DAP (diâmetro a altura do peito) de árvores de E. benthamii, provenientes de três áreas de plantio comercial no Município de Guarapuava, PR, localizado no centro-oeste, no terceiro planalto, com coordenadas geográficas $25^{\circ} 23^{\prime} 26^{\prime \prime} \mathrm{S}$ e $51^{\circ} 27^{\prime} 15^{\prime \prime} \mathrm{E}$, e $1.120 \mathrm{~m}$ de altitude. A cobertura vegetal original da região compõe-se de campos limpos com estepes de gramíneas baixas e capões de Mata de Araucária. O clima é do tipo $\mathrm{Cfb}$, subtropical úmido, com verões frescos, geadas frequentes e sem estação seca, com temperatura variando de $6,8{ }^{\circ} \mathrm{C}$ a $36{ }^{\circ} \mathrm{C}$, com média de $16,8{ }^{\circ} \mathrm{C}$ e precipitação pluviométrica média anual de $1.938 \mathrm{~mm}$ (Salvador et al., 2005).

As áreas de coleta do material foram implantadas no ano de 2001 com mudas de sementes produzidas na APS (área de produção de sementes) da Embrapa Florestas. Essa APS foi implantada em 1988 com sementes de uma base genética de sete árvores de polinização livre, e têm como procedência geográfica Wentworth Falls - NSW, Austrália, com latitude de $33^{\circ} 48^{\prime} \mathrm{S}$, longitude de $150^{\circ}$ 24' E, altitude de $150 \mathrm{~m}$ e precipitação pluviométrica anual variando de $890 \mathrm{~mm}$ a $2.000 \mathrm{~mm}$.

Foram utilizados 91 indivíduos de $E$. benthamii com seis anos de idade (Tabela 1).

Tabela 1. Dados das áreas onde foram selecionadas árvores potenciais para avaliação do potencial energético.

\begin{tabular}{|c|c|c|c|c|c|c|}
\hline Área & Localização & Idade & Espaçamento & Área do plantio & $\mathbf{N A S}^{*}$ & Grau de seleção \\
\hline PFANN & Guarapuava, PR & 6 anos & $3 \mathrm{~m} \times 2 \mathrm{~m}$ & 8 ha & 36 & $370: 1$ \\
\hline Agrária & Guarapuava, PR & 6 anos & $3 \mathrm{~m} \times 2 \mathrm{~m}$ & 29 ha & 35 & $1.381: 1$ \\
\hline Roncador & Guarapuava, PR & 6 anos & $3 \mathrm{~m} \times 2 \mathrm{~m}$ & 6,3 ha & 20 & $525: 1$ \\
\hline
\end{tabular}

* NAS = número de árvores selecionadas. 
Os indivíduos foram selecionados com base em características dendrométricas e silviculturais. As características consideradas foram ausência de bifurcações ou defeitos no tronco, destaque no crescimento em diâmetro, ausência de sintomas ou defeitos provocados por geadas, pragas ou doenças. Os indivíduos selecionados foram cubados e abatidos para avaliação da densidade básica e poder calorífico. A caracterização dendrométrica das árvores constou de medidas de diâmetro à altura de $0,1 \mathrm{~m} ; 0,3 \mathrm{~m} ; 0,7 \mathrm{~m} ; 1,3$ $\mathrm{m} ; 3,3 \mathrm{~m}$; e 5,3 m, (seguindo com medidas de dois em dois metros, até a altura comercial $-\varnothing \geq 5 \mathrm{~cm}$ ). Com base nas informações de altura e diâmetro, foi calculado o volume total de cada árvore. Para isso, foi utilizada a equação de Smalian, somando-se os volumes individuais de cada seção avaliada (Campos \& Leite, 2006):

$\mathrm{V}=\mathrm{V}_{1}+\mathrm{V}_{2}+\mathrm{V}_{3} \ldots \mathrm{V}_{\mathrm{n}}$, ou onde:

$\mathrm{V}=\left\{\left[\pi / 40.000\left(\left(\mathrm{D}_{1}^{2}+\mathrm{D}_{2}^{2}\right) / 2\right) \times \mathrm{L}_{1}\right)\right]+\ldots+$ $\left.\left.\left[\pi / 40.000\left(\left(\mathrm{D}_{\mathrm{n}-1}^{2}+\mathrm{D}_{\mathrm{n}}^{2}\right) / 2\right) \times \mathrm{L}_{\mathrm{n}-1}\right)\right]\right\}$, em que:

$\mathrm{D}_{1}$ : maior diâmetro da seção 1 ;

$\mathrm{D}_{2}$ : menor diâmetro da seção 1 ;

$\mathrm{L}_{1}$ : comprimento da seção 1 .

n: última seção comercial.

Para o cálculo do volume final da madeira, foi descontado 10\%, referente à casca (Silva, et al., 2004). Em seguida, foram coletados os discos do DAP e encaminhados para o Laboratório de Tecnologia da Madeira da Embrapa Florestas, para as análises. Foram coletados discos somente do DAP, pois a literatura mostra que a densidade básica observada nesta região é praticamente igual à densidade média da árvore para esta espécie (Pereira et al., 2000). As características avaliadas na madeira foram: densidade básica $\left(\mathrm{g} \mathrm{cm}^{-3}\right)$ segundo a norma NBR 11941/2003 (Associação Brasileira de Normas Técnicas, 2003), o poder calorífico ( $\mathrm{kcal} \mathrm{kg}^{-1}$ ) segundo a norma NBR 8633/1984 (Associação Brasileira de Normas Técnicas, 1984) e em seguida calculados a densidade energética (equação 1) e o potencial energético individual (equação 2).

\section{Equação 1:}

$\mathrm{DE}=\mathrm{DB} * \mathrm{PCS}$, em que:

DE: densidade energética $\left(\mathrm{kcal} \mathrm{m}^{-3}\right)$;

DB: densidade básica $\left(\mathrm{kg} \mathrm{m}^{-3}\right)$;

PCS: poder calorífico superior $\left(\mathrm{kcal} \mathrm{kg}^{-1}\right)$.

\section{Equação 2:}

PEI $=$ PCS $*$ MA, onde:

PCS: poder calorífico superior $\left(\mathrm{kcal} \mathrm{kg}^{-1}\right)$;

MA: massa individual $(\mathrm{kg})$;
Para obtenção do carvão em laboratório, cunhas foram secas em estufa a $105 \pm 5^{\circ} \mathrm{C}$. As carbonizações foram realizadas em forno elétrico (mufla) adaptado com controle de temperatura automático e incrementos de $5,3{ }^{\circ} \mathrm{C} \cdot \mathrm{min}^{-1}$ até $180^{\circ} \mathrm{C}$, passando para $1^{\circ} \mathrm{C} \mathrm{min}{ }^{-1}$ até $500^{\circ} \mathrm{C}$, permanecendo por duas horas nesta temperatura. O tempo total de carbonização foi de oito horas.

$\mathrm{Na}$ avaliação do carvão foi realizada a análise imediata (teor de carbono fixo, matérias voláteis, matérias condensáveis e cinzas) segundo a norma NBR 8112/1986 (Associação Brasileira de Normas Técnicas, 1986) e o poder calorífico superior pela norma NBR 11941/2003 (Associação Brasileira de Normas Técnicas, 2003). Com base no rendimento do carvão e seu poder calorífico foi estimado o potencial energético individual.

\section{Análise estatística}

A partir das características mensuradas, no campo e laboratório para cada indivíduo, procederam-se as análises multivariadas dos componentes principais e de fator com o objetivo de reduzir o número de variáveis e identificar aquelas que apresentam maior contribuição para a variância total (Duarte, 1997; Manly, 1986). O software utilizado para aplicação das análises multivariadas foi o programa SAS (System Analysis Statistic).

As correlações entre as características dendrométricas e de qualidade energética da madeira foram estimadas pelo coeficiente de Pearson (r).

Pelo critério de Kaiser, retiveram para análise de fatores os componentes principais com autovalores superiores a 1 (um) desde que as variâncias acumuladas explicassem mais de $70 \%$ da variação total. Esses componentes foram submetidos à análise de fator. Numa análise fatorial, as variáveis que apresentaram comunalidades inferiores a 0,7 foram eliminadas e as restantes submetidas à nova análise até que todos atendessem esse critério.

Em seguida, foi realizada a rotação dos eixos para a melhor interpretação dos fatores, conforme descrito por Meyer \& Braga (1998) e Souza \& Khan (2001). A rotação foi realizada pelo método Varimax, que faz uma rotação ortogonal dos eixos. Essa rotação não afeta as comunalidades das variáveis e nem a proporção explicada da variância total.

Para o cálculo do fator de cada indivíduo, foi considerada a comunalidade e o valor observado de cada variável, dado pela seguinte expressão:

$\mathrm{F}_{\mathrm{i}}=\sum(\mathrm{CMi} * \mathrm{Voj})$, onde; 
$\mathrm{F}_{\mathrm{i}}$ : fator do indivíduo i;

$\mathrm{CM}_{\mathrm{i}}$ : comunalidade da variável j do indivíduo i;

$\mathrm{Vo}_{\mathrm{j}}$ : valor observado para a variável j no indivíduo i.

Através dos fatores de cada indivíduo foi estabelecida uma classificação em ordem decrescente.

\section{Resultados e discussão}

\section{Variabilidade das características de interesse energético}

As médias e as faixas de variabilidade das características dos indivíduos estão apresentadas na Tabela 2.

Tabela 2. Faixas de variabilidade das características de três plantios comerciais de E. benthamii de seis anos na região de Guarapuava, PR.

\begin{tabular}{|c|c|c|c|c|}
\hline \multicolumn{5}{|c|}{ Avaliação da madeira } \\
\hline Característica $^{1}$ & Média & Limite inferior & Limite superior & $\Delta(\%)^{2}$ \\
\hline Densidade básica $\left(\mathrm{kg} \mathrm{m}^{-3}\right)$ & $0,475 \pm 0,039 *$ & 0,436 & 0,514 & 17,9 \\
\hline Volume $\left(\mathrm{m}^{3}\right.$ indivíduo $\left.^{-1}\right)$ & $0,527 \pm 0,125$ & 0,402 & 0,652 & 62,2 \\
\hline Massa (kg indivíduo ${ }^{-1}$ ) & $249,8 \pm 61,2$ & 188,6 & 311 & 64,9 \\
\hline Poder calorífico $\left(\mathrm{kcal} \mathrm{kg}^{-1}\right)$ & $4.681 \pm 487,6$ & $4.193,4$ & $5.168,6$ & 23,3 \\
\hline Dens. energética $\left(\mathrm{kcal} \mathrm{m}^{-3}\right)$ & $2.222 \pm 277,4$ & $1.944,6$ & $2.499,4$ & 28,5 \\
\hline Pot. energ. (kcal indivíduo-1) & $1.164 .466 \pm 300.116$ & 864.349 & 1.464 .582 & 69,4 \\
\hline \multicolumn{5}{|c|}{ Avaliação do carvão } \\
\hline Característica $^{1}$ & Média & Limite inferior & Limite superior & $\Delta(\%)$ \\
\hline Rendimento do carvão (\%) & $34,86 \pm 1,7$ & 33,16 & 36,56 & 10,3 \\
\hline Rend. licor pirolenhoso (\%) & $39,64 \pm 2,7$ & 36,94 & 42,34 & 14,6 \\
\hline Rendimento de gases (\%) & $25,56 \pm 2,6$ & 22,96 & 28,16 & 22,6 \\
\hline Teor de carbono fixo (\%) & $81,85 \pm 3,5$ & 78,35 & 85,35 & 8,9 \\
\hline Teor de mat. voláteis (\%) & $17,17 \pm 3,6$ & 13,57 & 20,77 & 53,1 \\
\hline Teor de cinzas $(\%)$ & $0,96 \pm 0,3$ & 0,66 & 1,26 & 90,9 \\
\hline Poder cal. (kcal kg ${ }^{-1}$ ) & $8.777 \pm 520$ & 8.257 & 9.297 & 12,6 \\
\hline Pot. energ. (kcal indivído ${ }^{-1}$ ) & $765.177 \pm 198.342$ & 566.834 & 963.519 & 70,0 \\
\hline
\end{tabular}

${ }^{1}$ Média de 91 matrizes. ${ }^{2}$ Variação do limite superior em relação ao limite inferior. * $\mathrm{p}<0,05$.

A densidade básica, os rendimentos de carvão e licor pirolenhoso, teor de carbono fixo e o poder calorífico do carvão apresentaram variabilidades menores, sendo inferiores a $20 \%$, na comparação entre o limite superior e o limite inferior do intervalo de confiança da média (Tabela 2). O poder calorífico da madeira, a densidade energética e o rendimento de gases apresentaram variabilidade intermediária. Observase que as características que apresentaram maiores variações foram o volume $(62,2 \%)$, massa $(64,9 \%)$, potencial energético da madeira $(69,4 \%)$ e potencial energético do carvão (70\%).

A densidade básica média observada $\left(0,475 \mathrm{~g} \mathrm{~cm}^{-3}\right)$ foi maior que a densidade básica do $E$. grandis $(0,391 \mathrm{~g}$ $\left.\mathrm{cm}^{-3}\right)$ e similar ao E. saligna $\left(0,476 \mathrm{~g} \mathrm{~cm}^{-3}\right)$ implantados em Salesópolis, SP, avaliados aos 10 anos de idade (Brito et al., 1983). Thomaz (2007) caracterizou árvores de $E$. benthamii com 18 anos de idade e a densidade observada pelo autor foi de $0,529 \mathrm{~g} \mathrm{~cm}^{-3}$.

Observa-se na Tabela 2 que o volume médio por árvore foi de $0,527 \mathrm{~m}^{3}$, com variação de 0,402 a 0,652 $\mathrm{m}^{3}$ indivíduo $\mathrm{o}^{-1}$. Considerando o espaçamento de plantio ( $3 \mathrm{~m} \times 2 \mathrm{~m}$ ), a produtividade média estimada do $E$. benthamii foi de $878 \mathrm{~m}^{3} \mathrm{ha}^{-1}$, superior ao E. saligna $\left(852 \mathrm{~m}^{3} \mathrm{ha}^{-1}\right)$ e inferior ao E. grandis $\left(1.105 \mathrm{~m}^{3} \mathrm{ha}^{-1}\right)$, ambos aos 10 anos de idade (Brito et al., 1983), e com IMA (incremento médio anual) também superior, com 146,85 e $110 \mathrm{~m}^{3}$ ha $a \mathrm{ano}^{-1}$, respectivamente. Quanto à produtividade média, foi de 416 ton $\mathrm{ha}^{-1}$ aos 6 anos, sendo superior ao E. saligna $(405,6$ ton ha-1) e inferior ao E. grandis (518,2 $\mathrm{Mg} \mathrm{ha}^{-1}$ ) aos 10 anos (Brito et al., 1983). No entanto, o poder calorífico da madeira foi de $4.681 \mathrm{kcal} \mathrm{kg}^{-1}$, ligeiramente inferior ao observado por Thomaz (2007), que quantificou em $4.887 \mathrm{kcal} \mathrm{kg}^{-1} \mathrm{o}$ 
poder calorífico de $E$. benthamii com 18 anos. O poder calorífico observado neste trabalho ficou em posição intermediária entre 16 espécies do gênero Eucalyptus, conforme revisão realizada por Quirino et al. (2005). Nesta revisão, o maior poder calorífico das espécies de eucalipto foi do E. pellita $\left(5.023 \mathrm{kcal} \mathrm{kg}^{-1}\right)$ e o menor foi do E. urophilla $\left(4.422 \mathrm{kcal} \mathrm{kg}^{-1}\right)$.

A densidade energética está relacionada à energia contida num determinado volume de madeira. Neste trabalho, a densidade energética média da madeira foi de $2.222 \mathrm{kcal} \mathrm{m}^{-3}$. Este resultado é superior ao encontrado por Brito et al., (1983) para o E. grandis $\left(2.080 \mathrm{kcal} \mathrm{m}^{-3}\right)$, equivalente ao E. globulus $\left(2.240 \mathrm{kcal} \mathrm{m}^{-3}\right)$ e inferior ao E. citriodora $\left(3.440 \mathrm{kcal} \mathrm{m}^{-3}\right)$.

A produtividade energética por unidade de área permite uma melhor visualização do potencial energético da cultura. A média de produtividade energética estimada do E. benthamii (considerando população de 1.666 plantas ha-1) foi de $1.940 \mathrm{Gcal} \mathrm{ha}^{-1}$ aos seis anos. Brito et al. (1983) estimou o potencial energético de oito espécies de eucalipto. A produtividade energética variou de 300 Gcal.ha ${ }^{-1}$ para o E. gummifera até $2.500 \mathrm{Gcal} \mathrm{ha}^{-1}$ para o E. pilularis. Lima (2000) avaliou a produtividade e equivalência energética de Eucalyptus sp. em relação ao óleo combustível e à energia elétrica. $\mathrm{O}$ autor estimou produtividades energéticas de $450 \mathrm{Gcal} \mathrm{ha}^{-1}$ e $900 \mathrm{Gcal}$ ha $^{-1}$ para o E. grandis e E. paniculata, respectivamente. A produtividade energética anual do E. bentamii (323 Gcal ha $\mathrm{ano}^{-1}$ ) foi superior ao observado por Urquiaga et al. (2005) para o etanol (161 Gcal ha-1 $)$ e para o biodiesel a partir do dendê (154 Gcal ha'-1).

O rendimento médio do carvão foi de $34,9 \%$, próximo aos valores encontrados por Thomaz (2007) para $E$. benthamii aos 18 anos $(34,0 \%)$ e por Pereira et al. (1997) para a mesma espécie, aos sete anos (34,2\%). Comparado às outras espécies, foi ligeiramente superior ao E. grandis $(33,3 \%)$ e ao E. saligna e inferior ao $E$. triantha $(37,8 \%)$ e ao E. microcorys $(35,9 \%)$ (Brito et al., 1983). Trugilho et al. (2005), trabalhando com seis clones de híbridos de eucalipto, observaram rendimentos que variaram de $35,9 \%$ a $40,2 \%$. No entanto, a temperatura final de carbonização foi de $450{ }^{\circ} \mathrm{C}$, permanecendo por
30 minutos nesta temperatura. A menor temperatura de carbonização associada ao menor tempo de residência pode explicar o maior rendimento observado por estes autores.

O poder calorífico médio do carvão foi de $8.777 \mathrm{kcal}$ $\mathrm{kg}^{-1}$ (Tabela 2). Este valor está acima do observado por Thomaz (2007) para E. benthamii aos 18 anos (6.569 $\left.\mathrm{kcal} \mathrm{kg}^{-1}\right)$. O poder calorífico médio do carvão observado neste trabalho foi superior ao poder calorífico $(8.255$ $\mathrm{kcal} \mathrm{kg}^{-1}$ ) encontrado por Vella et al. (1989) para o $E$. tereticornis com nove anos de idade em Viçosa, MG.

O Estado de São Paulo apresenta padrões mínimos de qualidade, física, química e de produção de carvão vegetal como base para certificação de produtos, estabelecidos pela norma PMQ 3-03 (São Paulo, 2003). Esta norma estabelece que, quanto à qualidade química, o carvão vegetal deve apresentar teor de carbono fixo mínimo de $75 \%$ e teor de cinzas abaixo de $1,5 \%$. Neste trabalho, pôde ser observado que os valores médios de carbono fixo $(81,8 \%)$ e cinzas $(0,9 \%)$ revelados pela análise imediata no $E$. benthamii estão de acordo com esta norma.

\section{Correlações entre as variáveis}

$\mathrm{Na}$ Tabela 3 estão apresentadas as correlações entre as variáveis estudadas. Considera-se que duas variáveis possuem associação entre si quando o coeficiente de correlação foi significativo a $5 \%$ de probabilidade. No entanto, somente as correlações significativas e consideradas altas (maiores que 0,8 ) foram discutidas neste trabalho.

A massa da madeira apresentou correlação positiva com o volume $(0,93)$. Este resultado pode ser considerado normal, pois na estimativa da massa foi considerado o volume e a densidade básica, sendo, portanto, diretamente proporcional. $\mathrm{O}$ volume também apresentou correlação positiva com o potencial energético da madeira $(0,87)$ e potencial energético do carvão $(0,90)$. Estas correlações também eram esperadas, pois quanto maior o volume, maiores serão os potenciais energéticos da madeira e do carvão. Da mesma forma, a massa apresentou correlações positivas com os potenciais energéticos da madeira $(0,92)$ e do carvão $(0,97)$. 
Tabela 3. Coeficientes de correlação linear entre as a características dendrométricas e energéticas de 91 indivíduos de $E$. benthamii aos seis anos, no Município de Guarapuava, PR.

\begin{tabular}{llllllllllllll}
\hline Variável & PEC & PCC & TCZ & TMV & TCF & RG & RL & RC & PEM & DEM & PCM & MA & VOL \\
\hline DBM & $0,29^{* *}$ & $0,22^{*}$ & $-0,16$ & 0,07 & $-0,06$ & $-0,06$ & 0,07 & $-0,01$ & 0,19 & $0,56^{* *}$ & $-0,11$ & $0,25^{*}$ & $-0,09$ \\
VOL & $0,90^{* *}$ & $-0,07$ & $-0,12$ & 0,08 & $-0,06$ & $-0,25^{*}$ & 0,14 & 0,18 & $0,87^{* *}$ & $-0,18$ & $-0,14$ & $0,93^{* *}$ & \\
MA & $0,97^{* *}$ & 0,01 & $-0,16$ & 0,11 & $-0,09$ & $-0,27^{*}$ & 0,15 & 0,19 & $0,92^{* *}$ & 0,02 & $-0,17$ & \\
PCM & $-0,18$ & $-0,04$ & 0,07 & $-0,09$ & 0,09 & 0,01 & 0,05 & $-0,09$ & $0,23^{*}$ & $0,76^{* *}$ & & \\
DEM & 0,03 & 0,10 & $-0,04$ & $-0,03$ & 0,04 & $-0,03$ & 0,09 & $-0,09$ & $0,31^{* *}$ & & & \\
PEM & $0,89^{* *}$ & $-0,01$ & $-0,13$ & 0,08 & $-0,07$ & $-0,27^{*}$ & 0,16 & 0,16 & & & & \\
RC & $0,27^{* *}$ & $-0,44^{* *}$ & $-0,01$ & $0,68^{* *}$ & $-0,69^{* *}$ & $-0,33^{* *}$ & $-0,32^{* *}$ & & & & & \\
RL & 0,14 & $0,29^{* *}$ & 0,01 & $-0,25^{*}$ & $0,26^{*}$ & $-0,79^{* *}$ & & & & & & \\
RG & $-0,31^{* *}$ & 0,00 & $-0,00$ & $-0,19$ & 0,20 & & & & & & & \\
TCF & $-0,11$ & $0,46^{* *}$ & 0,11 & $-1,00$ & & & & & & & & \\
TMV & 0,12 & $-0,45^{* *}$ & $-0,19$ & & & & & & & & & & \\
TCZ & $-0,16$ & $-0,05$ & & & & & & & & & & & \\
PCC & 0,15 & & & & & & & & & & & &
\end{tabular}

*, ** Significativo a $5 \%$ e $1 \%$, respectivamente. $\mathrm{PEC}=$ potencial energético do carvão; $\mathrm{MA}=$ massa da madeira; PEM = potencial energético da madeira; $\mathrm{VOL}=$ volume da madeira; $\mathrm{TCF}=$ teor de carbono fixo; $\mathrm{RC}=$ rendimento do carvão; $\mathrm{TMV}=$ teor de matérias voláteis; $\mathrm{DEM}=$ densidade energética da madeira; $\mathrm{PCM}$ = poder calorífico da madeira; $\mathrm{RG}=$ rendimento de gases; $\mathrm{RLP}=$ rendimento de licor pirolenhoso; $\mathrm{DBM}=$ densidade básica da madeira.

\section{Análise dos componentes principais}

Os componentes principais apresentaram autovalores que variaram de 0 a 4,1. Constatou-se que, somente os cinco primeiros componentes apresentaram autovalores maiores que 1 e explicaram $95,88 \%$ da variação total (Tabela 4).

Tabela 4. Autovalores dos componentes principais (em negrito) extraídos da matriz de correlação das características de E. benthamii.

\begin{tabular}{cccc}
\hline $\begin{array}{c}\text { Componentes } \\
\text { principais }\end{array}$ & Autovalor & $\begin{array}{c}\text { Variação } \\
\text { total (\%) }\end{array}$ & $\begin{array}{c}\text { Variação } \\
\text { acumulada (\%) }\end{array}$ \\
\hline $\mathbf{1}$ & $\mathbf{4 , 1 1 4 0 8}$ & 34,28 & 34,28 \\
$\mathbf{2}$ & $\mathbf{2 , 6 8 1 3 9}$ & 22,34 & 56,63 \\
$\mathbf{3}$ & $\mathbf{1 , 9 7 7 1 8}$ & 16,48 & 73,11 \\
$\mathbf{4}$ & $\mathbf{1 , 5 8 5 4 8}$ & 13,21 & 86,32 \\
$\mathbf{5}$ & $\mathbf{1 , 1 4 7 8 6}$ & 9,57 & 95,88 \\
6 & 0,45325 & 3,78 & 99,66 \\
7 & 0,02801 & 0,23 & 99,89 \\
8 & 0,00576 & 0,05 & 99,94 \\
9 & 0,00341 & 0,03 & 99,97 \\
10 & 0,00188 & 0,02 & 99,99 \\
11 & 0,00157 & 0,01 & 100,00 \\
12 & 0,00012 & 0,00 & 100,00 \\
\hline
\end{tabular}

Os primeiros cinco componentes principais foram submetidos à análise de fator. Numa primeira análise, foram eliminadas as variáveis que apresentaram comunalidade menor que 0,7 (poder calorífico do carvão e teor de cinzas) e as demais foram mantidas. A análise dos fatores rotacionados (Tabela 5), por meio do método Varimax, permitiu verificar a importância de cada variável dentro de cada fator. As variáveis consideradas importantes foram as que apresentaram coeficiente de correlação igual ou maior que 0,7 e estão destacadas em negrito.

O fator 1 explicou $34,28 \%$ da variação total e está associado às variáveis volume, massa, potencial energético da madeira e potencial energético do carvão. No entanto, os potenciais energéticos da madeira e do carvão estão intimamente ligados ao potencial de crescimento de cada indivíduo (volume e massa). Este fator pode ser considerado como fator energético. $\mathrm{O}$ potencial energético da madeira depende da massa e do poder calorífico da madeira. Nota-se na Tabela 2 que a maior variação ocorreu na massa $(64,9 \%)$, comparada ao poder calorífico $(23,3 \%)$. Possivelmente, a massa apresenta papel mais importante na determinação do potencial energético da madeira, comparada ao poder calorífico. Já o potencial energético do carvão depende da massa da madeira, do rendimento do carvão e do poder calorífico do carvão. Destas três variáveis, a que apresentou maior variação foi a massa $(64,9 \%)$, comparada ao rendimento do carvão $(10,3 \%)$ e poder calorífico do carvão $(11,6 \%)$. 
Tabela 5. Fatores rotacionados obtidos através da matriz de correlação das variáveis pelo método Varimax.

\begin{tabular}{lcccccc}
\hline \multirow{2}{*}{ Variáveis $^{*}$} & \multirow{2}{*}{$\mathbf{C M}^{* *}$} & Fator 2 & Fator 3 & Fator 4 & Fator 5 \\
\cline { 2 - 7 } & & Fator 1 & Fatores & **** \\
\hline PEC & 0,97570654 & $\mathbf{0 , 9 5 3 0 8}$ & 0,15006 & $-0,10540$ & 0,15040 & 0,10481 \\
MA & 0,99486461 & $\mathbf{0 , 9 5 1 0 5}$ & 0,18757 & $-0,13207$ & 0,18242 & 0,06680 \\
PEM & 0,99317938 & $\mathbf{0 , 8 9 9 9 3}$ & 0,28056 & 0,16055 & 0,20802 & $-0,18853$ \\
VOL & 0,99001033 & $\mathbf{0 , 8 9 1 9 7}$ & 0,16215 & $-0,31095$ & 0,15114 & $-0,22040$ \\
TCF & 0,93137164 & $-0,31120$ & $\mathbf{0 , 8 7 3 9 2}$ & $-0,24519$ & 0,10297 & 0,00861 \\
RC & 0,75459232 & 0,40939 & $\mathbf{- 0 , 7 4 3 2 4}$ & 0,12916 & $-0,07884$ & $-0,10814$ \\
TMV & 0,92488277 & 0,32356 & $\mathbf{- 0 , 8 6 6 3 3}$ & 0.24595 & $-0,09571$ & 0,00292 \\
DEM & 0,99853042 & 0,05874 & 0,30922 & $\mathbf{0 , 9 3 8 4 7}$ & 0,12978 & 0,04358 \\
PCM & 0,99868772 & $-0,10107$ & 0,26906 & $\mathbf{0 , 7 4 7 7 4}$ & 0,08193 & $-0,59182$ \\
RG & 0,97471012 & $-0,46638$ & $-0,02902$ & $-0,11144$ & $\mathbf{0 , 8 6 1 9 9}$ & 0,03014 \\
RLP & 0,97239747 & 0,20309 & 0,51806 & 0,03042 & $\mathbf{- 0 , 8 1 2 5 0}$ & 0,04100 \\
DBM & 0,99705910 & 0,23275 & 0,12159 & 0,48536 & 0,10367 & $\mathbf{0 , 8 2 5 7 0}$ \\
\hline
\end{tabular}

"PEC = potencial energético do carvão; MA = massa da madeira; PEM = potencial energético da madeira; VOL = volume da madeira; $\mathrm{TCF}=$ teor de carbono fixo; $\mathrm{RC}=$ rendimento do carvão; $\mathrm{TMV}=$ teor de matérias voláteis; $\mathrm{DEM}=$ densidade energética da madeira; $\mathrm{PCM}=$ poder calorífico da madeira; $\mathrm{RG}=$ rendimento de gases; $\mathrm{RLP}=$ rendimento de licor pirolenhoso; $\mathrm{DBM}=$ densidade básica da madeira. ${ }^{* *} \mathrm{CM}=$ comunalidade. ${ }^{* * *}$ Fator 1 = volume, massa, potencial energético da madeira e potencial energético do carvão; Fator $2=$ contrastes de teor de matérias voláteis $v s$ teor de carbono fixo e rendimento de carvão $v s$ teor de carbono fixo; Fator $3=$ poder calorífico da madeira e densidade energética da madeira; Fator 4 = contraste do rendimento de licor pirolenhoso $v s$ rendimento de gases; Fator 5 = densidade.

O fator 2, responsável por $22,3 \%$ da variação total, está associado a dois contrastes, teor de carbono fixo $\mathrm{x}$ rendimento de carvão e teor de carbono fixo x teor de matérias voláteis do carvão. Este fator está associado às variáveis do carvão. Isto permite chamar este fator de "fator de carbonização". O teor de carbono fixo indica o "grau de pureza" do carvão, sendo inversamente proporcional ao seu rendimento. O teor de matérias voláteis é complementar ao teor de carbono fixo e de cinzas contidos no carvão e revelados pela análise imediata, por isso, o contraste entre estas duas variáveis já era esperado.

O fator 3 explicou $16,48 \%$ da variação total, e está relacionado ao poder calorífico da madeira e a sua densidade energética. Estas constatações permitem chamar de fator da "Madeira". A densidade energética da madeira é o produto do volume pelo poder calorífico da madeira, estando, portanto, correlacionados positivamente (Tabela 3 ).

\section{Classificação dos indivíduos}

Os fatores e os índices calculados de cada indivíduo estão apresentados na Tabela 6 .

Com relação aos fatores, destacaram-se a matriz 33 com fator 3.697 .562 e a matriz 22 com fator 2.978.633 que, comparados à média geral, foram superiores em 102\% e 63\%, respectivamente. Das 91 matrizes avaliadas, 49 foram superiores à média geral (1.826.929). Assim, qualquer descarte em estudos futuros deve ser bem avaliado, pois a partir da terceira classificada (matriz 27), as diferenças foram bastante estreitas (Tabela 6).

Além disso, ainda não se sabe qual o comportamento desses indivíduos em relação à capacidade e vigor da rebrota e à capacidade de enraizamento. Por isso, sugere-se que sejam realizadas avaliações de campo para avaliação da rebrota. 
Tabela 6. Índices dos indivíduos de E. benthamii de acordo com o fator 1 (massa, volume, potencial energético da madeira e potencial energético do carvão).

\begin{tabular}{|c|c|c|c|c|c|c|c|c|c|c|c|c|c|c|}
\hline$N^{0}$ ind & Ind & CLA & $N^{0}$ ind & Ind & CLA & $N^{\circ}$ ind & Ind & CLA & $\mathrm{N}^{0}$ ind & Ind & CLA & $\mathrm{N}^{0}$ ind & Ind & CLA \\
\hline 33 & 3.697 .562 & 1 & 47 & 2.175 .087 & 20 & 37 & 1.975 .006 & 39 & 15 & 1.650 .086 & 58 & 53 & 1.355 .044 & 77 \\
\hline 22 & 2.978 .633 & 2 & 56 & 2.166 .711 & 21 & 26 & 1.962 .160 & 40 & 45 & 1.635 .645 & 59 & 83 & 1.330 .249 & 78 \\
\hline 27 & 2.538 .389 & 3 & 30 & 2.152 .360 & 22 & 61 & 1.955 .880 & 41 & 54 & 1.610 .488 & 60 & 9 & 1.306 .817 & 79 \\
\hline 48 & 2.493 .932 & 4 & 31 & 2.129 .416 & 23 & 12 & 1.954 .251 & 42 & 11 & 1.600 .783 & 61 & 89 & 1.299 .743 & 80 \\
\hline 34 & 2.413 .614 & 5 & 18 & 2.123 .404 & 24 & 57 & 1.953 .625 & 43 & 78 & 1.585 .720 & 62 & 91 & 1.283 .658 & 81 \\
\hline 38 & 2.370 .712 & 6 & 29 & 2.116 .245 & 25 & 55 & 1.944 .849 & 44 & 90 & 1.581 .908 & 63 & 81 & 1.231 .956 & 82 \\
\hline 66 & 2.368 .019 & 7 & 69 & 2.105 .858 & 26 & 63 & 1.916 .339 & 45 & 25 & 1.529 .167 & 64 & 76 & 1.213 .176 & 83 \\
\hline 67 & 2.362 .380 & 8 & 59 & 2.091 .402 & 27 & 10 & 1.909 .405 & 46 & 8 & 1.516 .344 & 65 & 84 & 1.193 .449 & 84 \\
\hline 43 & 2.318 .024 & 9 & 50 & 2.080 .958 & 28 & 17 & 1.901 .025 & 47 & 62 & 1.485 .233 & 66 & 80 & 1.161 .762 & 85 \\
\hline 49 & 2.311 .228 & 10 & 24 & 2.057 .764 & 29 & 71 & 1.876 .643 & 48 & 21 & 1.465 .388 & 67 & 88 & 1.159 .707 & 86 \\
\hline 35 & 2.303 .373 & 11 & 4 & 2.056 .371 & 30 & 1 & 1.851 .595 & 49 & 6 & 1.443 .477 & 68 & 85 & 1.156 .539 & 87 \\
\hline 42 & 2.280 .116 & 12 & 32 & 2.029 .672 & 31 & 44 & 1.824 .769 & 50 & 40 & 1.437 .865 & 69 & 74 & 1.074 .688 & 88 \\
\hline 14 & 2.267 .340 & 13 & 41 & 2.026 .955 & 32 & 39 & 1.729 .224 & 51 & 65 & 1.432 .311 & 70 & 72 & 1.033 .978 & 89 \\
\hline 60 & 2.230 .085 & 14 & 36 & 2.022 .628 & 33 & 46 & 1.715 .531 & 52 & 77 & 1.421 .618 & 71 & 79 & 988.504 & 90 \\
\hline 52 & 2.222 .679 & 15 & 23 & 2.017 .706 & 34 & 7 & 1.714 .633 & 53 & 2 & 1.414 .261 & 72 & 75 & 964.019 & 91 \\
\hline 70 & 2.214 .494 & 16 & 68 & 2.008 .887 & 35 & 20 & 1.681 .683 & 54 & 82 & 1.413 .144 & 73 & \multirow{3}{*}{\multicolumn{3}{|c|}{ Média geral $=1.826 .929$}} \\
\hline 28 & 2.204 .620 & 17 & 19 & 2.000 .938 & 36 & 5 & 1.681 .557 & 55 & 13 & 1.408 .535 & 74 & & & \\
\hline 51 & 2.202 .163 & 18 & 64 & 1.993 .978 & 37 & 58 & 1.657 .168 & 56 & 87 & 1.356 .402 & 75 & & & \\
\hline 16 & 2.181 .966 & 19 & 73 & 1.978 .067 & 38 & 3 & 1.654 .149 & 57 & 86 & 1.355 .657 & 76 & & & \\
\hline
\end{tabular}

$\mathrm{N}^{\circ} \mathrm{IND}=$ número do indivíduo; IND = índice de cada indivíduo de acordo com o fator 1; CLA = classificação dos indivíduos em ordem decrescente.

\section{Conclusões}

Existem diferenças entre indivíduos quanto à produtividade energética, sendo que, as maiores variações ocorreram nas variáveis: volume, massa, potencial energético da madeira, teor de cinzas e potencial energético do carvão.

Pelo menos duas matrizes (33 e 22) apresentaram potencial superior e merecem especial atenção no que se refere à possibilidade de clonagem para testes futuros.

$\mathrm{Na}$ seleção de indivíduos de E. benthamii para produção de energia, deve-se dar maior importância para as variáveis: massa, volume, potencial energético da madeira e potencial energético do carvão.

\section{Agradecimentos}

Á Luiz Carlos Valtrin, sócio gerente da Golden Tree, pela seleção e coleta das matrizes em campo.

\section{Referências}

ASSOCIAÇÃO BRASILEIRA DE NORMAS TÉCNICAS. NBR 8633: Carvão vegetal: determinação do poder calorífico: método de ensaio. Rio de Janeiro, 1984, 13p.

ASSOCIAÇÃO BRASILEIRA DE NORMAS TÉCNICAS. NBR 8112: Carvão vegetal: análise imediata: método de ensaio. Rio de Janeiro, 1986, 5p.

ASSOCIAÇÃO BRASILEIRA DE NORMAS TÉCNICAS.

NBR 11941: madeira: determinação da densidade básica. Rio de Janeiro, 2003, 6p.

BRASIL. MINISTÉRIO DE MINAS E ENERGIA. Empresa de Pesquisa Energética. Balanço Energético Nacional 2010: Ano base 2009. Resultados Preliminares / Ministério de Minas e Energia. Empresa de Pesquisa Energética - Rio de Janeiro: EPE, 2010, 54p. Disponível em: <https://ben.epe.gov.br/downloads/ Resultados_Pre_BEN_2010.pdf $>$. Acesso em: 10 jun. 2010.

BRITO, J. O.; BARRICHELO, L. E. G.; SEIXAS, F.;

MIGLIORINI, A. J.; MURAMOTO, M. C. Análise da Produção Energética e de Carvão Vegetal de Espécies de Eucalipto. IPEF, n. 23, p. 53-56, 1983.

BRITO, J. O.; CINTRA, T. C. Madeira para energia no Brasil: realidade, visão estratégica e demanda de ações. Biomassa \& Energia, v.1, n.2, p.157-163, 2004. 
BRITO, J. O. O uso energético da madeira. Estudos Avançados, v. 21, n. 59, p. 185-193. 2007. Disponível em: <www.scielo.br/ pdf/ea/v21n59/a14v2159.pdf>. Acesso em: 05 fev. 2009.

CAMPOS, J.C.C.; LEITE, H.G. Mensuração florestal. Editora UFV, Viçosa, MG, 2 ed., 2006, 470p.

COUTO, L.; MULLER, M.D.; TSUKAMOTO FILHO, A.A.. I Conferência Sustentabilidade na geração e uso de energia no Brasil: os próximos vinte anos. Campinas, SP, 2002. Disponível em: <http://www.cgu.unicamp.br/energia2020/ papers/paper_ Couto.pdf $>$. Acesso em: 15 set. 2007.

DUARTE, J.B. Princípios e utilização de técncias multivariadas no melhoramento de plantas. Monografia. Departamento de Genética. ESALQ-USP. Piracicaba. 1997.

INSTITUTO NACIONAL PARA EFICIÊNCIA ENERGÉTICA INEE. Política para a madeira energética. 2006, 16p.

LIMA, C.R.. Produtividade e equivalência energética de Eucalyptus sp. em relação ao óleo combustível e à energia elétrica. In: Encontro de energia no meio rural, n. 3, 2000, Campinas. Disponível em: <http://www.proceedings.scielo.br/scielo. php?script $=$ sci_arttext\&pid=MSC0000000022000000100007\&ln $\mathrm{g}=\mathrm{en} \& \mathrm{nrm}=\mathrm{abn}>$. Acesso em: 03 nov. 2007.

MANLY, B.F.J. Multivariate Statistical Methods- Primer. Ed Chapaman and Hall, London, 1986.

MEYER, L.F.; BRAGA, M.J. O crescimento das desigualdades tecnológicas na agricultura mineira. Revista de Economia e Sociologia Rural, Brasília, v. 36, n. 1, p.59-89, 1998.

PEREIRA, J.C.D.; SCHAITZA, E.G.; SHIMIZU, J.

Características físicas, químicas e rendimentos da destilação seca da madeira de Eucalyptus benthamii. Pesquisa em Andamento, Colombo, n. 35, 1997, 2p.

PEREIRA, J. C. D.; STURION, J. A.;HIGA, A. R.; HIGA, R. C. V.; SHIMIZU, J. Y.; Características da madeira de algumas espécies de eucalipto plantadas no Brasil. Série Documentos, Colombo, n. 38, 2000, 113p.

QUIRINO, W.F.; VALE, A.T.; ANDRADE, A.P.A.; ABREU, V.L.S.; AZEVEDO, A.C.S. Poder calorífico da madeira e de materiais ligno-celulósicos. Revista da Madeira, n. 89, 2005, p. 100-106. Disponível em: $<$ www.funtecg.org.br/arquivos/ podercalorifico.pdf $>$. Acesso em: 10 out. 2007.
SALVADOR, E.D.; COSTA, G.; TOMOTAKE, M.E.M.; JADOSKI, S.O. Levantamento preliminar da pteridoflora da região de Guarapuava (PR). Revista Ambiência, Guarapuava, PR v.1 n.2 p. 223-228 jul./dez. 2005. Disponível em: <http:// www.unicentro.br/editora/revistas/ambiencia/v1n2/223-228.pdf >. Acesso em: 15 out. 2007.

SILVA, H.D. da; FERREIRA, C.A.; CORRÊA, R.S.; BELLOTE, A.F.J.; TUSSOLINI, E.L. Alocação de biomassa e ajuste de equações para estimativa de biomassa em compartimentos aéreos de Eucalyptus benthamii. Boletim de Pesquisa Florestal, Colombo, n. 49, p. 83-95, 2004.

SÃO PAULO. Norma - PMQ 3-03. Norma que estabelece padrões mínimos de qualidade para carvão vegetal, 2003. Disponível em: $<$ http://www.codeagro.sp.gov.br/qualidade_sp/texto_word/novos_ arquivos/saa_10.doc >. Acesso em: 10 jun. 2007.

SOUZA, R.; KHAN, A.S. Modernização da agricultura e hierarquização dos municípios maranhenses. Revista de Economia e Sociologia Rural, Brasília, v. 39, n.1, p.75-98, 2001.

SOUZA, C.R.; ROSSI, L.M.B.; AZEVEDO, C.P.; LIMA, R.M. B. Comportamento da Acacia mangium e de clones de Eucalyptus grandis x E. urophylla em plantios experimentais na Amazônia Central. Scientia Florestalis, n.65, p.95-101, 2004.

THOMAZ, D.T. Avaliação da madeira e do carvão de Eucalyptus badjensis e Eucalyptus benthamii para uso energético.

Monografia, PUC-PR, 2007, 26p.

TRUGILHO, P.F.; LIMA, J.T.; MORI, F.A.; LINO, A.L. Avaliação de clones de Eucalyptus para produção de carvão vegetal. Revista Cerne, v.7, n.2, p.104-114, 2001.

TRUGILHO, P.F.; SILVA, J.R.M.; MORI, F.A.; LIMA, J.T; MENDES, L.M.; MENDES, L.F.B. Rendimentos e características do carvão vegetal em função da posição radial de amostragem em clones de Eucalyptus. Revista Cerne, Lavras, v. 11, n. 2, p. 178$186,2005$.

VELLA, M.M.C.F.; VALENTE, O.F.; VITAL, B.R.; LELLES, J.G. Influência da velocidade de carbonização da madeira nos rendimentos e nas propriedades do carvão produzido. Piracicaba, IPEF, n. 41/42, p.64-76, 1989.

URQUIAGA, S.; ALVES, B.J.R.; BODDEY, R.M. Produção de biocombustíveis: A questão do balanço energético. Revista de Política Agrícola, Brasília, n. 1, p.42-46, 2005. 